\title{
Examining the Relationship between Cultural Capital and Self-Efficacy: A Mixed Design Study on Teachers
}

\author{
By Yunus Emre Avci*, Rasim Tösten ${ }^{\dagger}$ \& Çiğdem Çelik Şahin
}

\begin{abstract}
Cultural capital expresses all the cultural acquisitions that individuals gain both through inheritance and through different channels in the course of their lives. Teachers' self-efficacy perceptions play an important role in their demonstrating more effort and responsibility to provide support to students' learning. The main purpose of this study is to examine the relationship between teachers' selfefficacies and cultural capital levels. The study was used an explanatory mixed method. In the quantitative part of the study, to measure cultural capital competencies of teachers, the "Cultural Capital Scale" developed by Tösten (2014) was used. As to measure teachers' self-efficacy perceptions, the "Teachers' Self-efficacy Scale" developed by Tschannen-Moran and Woolfolk Hoy (2001) and adapted into Turkish by Çapa, Çakıroğlu and Sarıkaya (2005) was used. In the qualitative part of the study, a structured interview form developed by the researchers was used. 885458 teachers working in Turkey compose the population of the quantitative part of the study. 2452 teachers determined by the stratified sampling technique participated in the study in the academic year of 2016-2017. As the sample strata, the development classification of the Ministry of Development was taken as a basis. The study group of the qualitative part consisted of 29 teachers who were determined by the easily accessible sampling method. As a result of the study, it was determined that the teachers' self-efficacy perceptions were "fairly adequate" and their cultural capital competencies were "moderate." When the relationship between teachers' self-efficacy perceptions and cultural capital competencies is examined, it is observed that there is a "positive" relationship at the "moderate" level. As a result of the analyses, cultural capital competencies that teachers had were found to be a significant predictor of self-efficacy perceptions. It was observed that the teachers put forward mainly intellectual accumulation when they were asked how cultural capital competencies and how the areas in which cultural capital competencies contribute to the perception of self-efficacy could be increased. The most mentioned areas by the teachers in relation to the things that could be done to increase cultural capital competencies were reading, participation in cultural activities, cultural education, and training.
\end{abstract}

Keywords: Self-efficacy, cultural capital, education.

*Lecturer, Siirt University, Turkey

'Lecturer, Siirt University, Turkey.

$\ddagger$ Teachers, Adana Science and Art Center, Turkey. 


\section{Introduction}

When examined the term "Cultural Capital" and "Self-Efficacy" in educational researches, it is seen that these terms are widespread in all around the world, in Asia, Europe and the US (Tavakoli, Pahlavannezhad, \& Ghansooly, 2017; Woulfe, 2008; Scholz et al., 2002; Cheng, 2011; De Graaf, De Graaf and Kraaykamp, 2000; Kim and Omizo, 2005; Goddard, Hoy, and Woolfolk-Hoy (2000). In one's life, cultural capital defines the class s/he belongs to, the achievement, roles and the way s/he brings up children. In the school context, the teachers are at the center of successful education of the students. After a detailed research on cultural capital, and its affects, it is considered that to focus on the relationship between cultural capital and self-efficacy of the teachers which is rarely studied. It is thought to present the results which are important for the educational area.

As indicated in the studies, the impact of the self-efficacy perceptions of teachers on the success of the learning process is a fact. Their cultural structure has an influence that extends to their professional achievements. The examination of the cultural capital competencies of teachers in Turkey, the impact on their selfefficacy perceptions, the contribution of cultural capital competencies to the selfefficacy perception, and how cultural capital competencies can be increased will reveal the impact on a successful education process. Besides, in these days when the success of education in Turkey is discussed, to investigate this issue and to make determinations based on scientific facts are also important.

It is believed that there is a relationship between teachers' self-efficacy beliefs and cultural capital competencies. It is important to examine the relationship between cultural capital and self-efficacy when it is considered that self-efficacy and cultural capital competencies have an effect on increasing the individuals' performance. The relationship between self-efficacy perceptions and cultural capital is a new research subject. It was observed that the studies in the international literature which examine the teachers' self-efficacy and cultural capital competency levels and the relationship between them were limited (Tavakoli, Pahlavannezhad, \& Ghansooly, 2017; Woulfe, 2008; Scholz et al., 2002). Therefore, it is estimated that the contribution of this study to the literature will be important since teachers' self-efficacy levels and cultural capital competencies, the relationship between them, the effect of cultural capital on selfefficacy perceptions and the increase of these competencies are examined in this study.

\section{Self-efficacy}

It is important that teachers, who are primarily responsible for the learning success, believe in themselves, are aware of their skills and are sure of their competencies. The efficacy belief refers to the knowledge, skills, and attitudes that are considered important for a role in the community, and the individual equivalent of it is self-efficacy (Yeşilyurt, 2013). Self-efficacy is the belief in competency to accomplish tasks, concerning one's motivational beliefs, values, 
goals (Eccles \& Wigfield, 2002) and self-confidence (Alivernini \& Lucidi, 2011). The self-efficacy belief is a matter which is considered important from the psychology and management knowledge point of view and has been studied frequently for the last thirty years. Self-efficacy derived from Bandura's (1997) social grip term is related to the beliefs or judgments of individuals on the competencies of accomplishing tasks or responsibilities. In other words, selfefficacy is the behaviors related to the one's belief in concepts such as awareness, knowledge, skills, perspectives, and needs that make up one's behaviors. Bandura (1986) defined self-efficacy as the belief in one's competencies exhibited at a particular level.

The high self-efficacy belief causes an individual to improve his/her performance by moving away from thoughts that negatively affect him/her and by finding the source of motivation that is needed. The low self-efficacy belief makes it more challenging to overcome difficulties encountered (Bussey \& Bandura, 1999). The beliefs of people in their own abilities affect not only their motivation but also the severity of stress and depression experienced in risky or stressful situations (Bandura, 1989). Emotional reactions can directly or indirectly affect actions by changing the process of thought. People who think they can get over the risks are less uncomfortable with the risks. They can reduce their stress and worries by controlling potential risks (Bandura, 1995). This is another key element of self-efficacy.

Self-efficacy is one of the important elements in the system that makes up human capacity. Similar skills and tasks exhibited by different people under different circumstances are related to the change in the self-efficacy beliefs of individuals. If individuals do not believe in the capacity and abilities they own or they hesitate, this capacity and equipment may not be adequately assessed. Therefore, the self-efficacy perception enables the complete fulfillment of tasks by using skills and coping with obstacles (White, 1982). A strong self-efficacy perception brings insistence, effort, and resistance with it. Moreover, the selfefficacy perception influences individuals' thinking styles, problem-solving skills, and emotional reactions. Individuals, whose self-efficacy perception is not at a sufficient level, have a narrower viewpoint and cannot solve the problems they encounter. On the contrary, people with high self-efficacy perceptions are in the sense of comfort and confidence even in challenging tasks (Kaptan \& Korkmaz, 2001).

It is indisputable that teachers' self-efficacy perceptions are necessary for success in the process of education that requires social interaction, motivation, and determination. Concerning this, Şahin (2010) states that even if teachers are sufficient in terms of their content knowledge, the lack of self-efficacy sense towards the teaching profession causes the learning and teaching process not to be productive. In this case, as the teachers' self-efficacy perceptions become stronger, it may mean that they will exhibit more endeavor and responsibility to support the learning of students (B1kmaz, 2006). Goddard, Hoy, and Woolfolk-Hoy (2000) argue that according to the social cognitive theory, social influence shapes individuals' self-efficacy beliefs. According to the theory, teachers' expectations of success positively influence students to make an effort to help their learning. Azar 
(2010) notes that the self-efficacy belief is a guiding element to the quality of teaching and the organization of teaching and learning environments.

Self-efficacy plays a vital role in the occurrence of self-confidence and motivation, and it is a fact that it is based on cultural differences (Woulfe, 2008). When investigating human behaviors, it is important to consider cultural differences. In the development of self-efficacy, when the importance of environmental factors is considered, the culture comes to the forefront among them (Scholz et al., 2002; Kim \& Omizo, 2005). Teachers, peers, and parents are factors that affect self-efficacy (Bandura, 1994). These factors vary according to the culture and depend heavily on the values of a particular culture. It is important to consider the culture when examining self-efficacy, and both self-efficacy and culture are vital components that make us (Woulfe, 2008).

The results of the study carried out by Woulfe (2008) revealed the relationship between self-efficacy and culture. The perception of self-efficacy is of great importance in achievement. It is clear that the factors such as parents, peers, and environment are important in the development of the perception of selfefficacy.

The self-efficacy perception is a structure mostly influenced by experience. For this reason, it is necessary to consider self-efficacy as a cultural element. It has been determined in cross-cultural studies that the self-efficacy perception differs from each other. While in individual cultures (such as the United States of America (USA) the self-efficacy perception is found to be high, in collectivist cultures (such as Asian countries) the self-efficacy perception is found to be low (Scholz et al., 2002).

Teachers, while fulfilling their duties, make their way from their personal beliefs, theories and community expectations. Practices in the school and classroom environment are also under the influence of the community. Therefore, the professional activities, personal beliefs and social value judgments of teachers are related to each other (Bek, 2007). Balc1 (1991) defines the teacher as an educator, exam applier, discipline provider, advocate of middle-class morality, and proxy. This definition can state that the culture of teachers is more likely to represent a middle-class cultural structure. The qualities of teachers will be effective on the generations they raise.

\section{Cultural Capital}

At this point, it is essential to mention the important views expressed by the French thinker Bourdieu on culture and cultural differences. Bourdieu's scientific initiative is based on the fact that the most profound logic of the social world can only be grasped, as a result of an in-depth investigation of an experimental reality that has a precise place and time in history. (Bourdieu, 1995). In this context, in regard to being produced on the French social structure, Bourdieu's theory of stratification is unique to the French society in some respects, however, if it is applied to other societies, it will likely point to a similar social structure beside the specific characteristics of that society. 
Bourdieu (1986) defined cultural capital as the "instruments for the appropriation of symbolic wealth socially designated as worthy of being sought and possessed", including social roles, language competency and refinement, general cultural background, knowledge, and skills (DeMarrais \& LeCompte, 1998). Lareau (2015) defined cultural capital as "skills individuals inherit that can be translated into different forms of value as people move through different institutions".

Interpreting cultural capital as familiarity with high-culture, some researchers have found positive effects of cultural capital on grades or educational attainment (DiMaggio, 1982; Kalmijn \& Kraaykamp, 1996; Werfhorst et al., 2003). Others have found parental reading behavior to be positively associated with children's educational attainment whereas Beaux-arts participation is not (De Graaf et al., 2000).

From a different point of view, the concept of cultural capital comes from the work of Blackledge (2001), Lareau (2003). Considering cultural capital as a resource that facilitates the compliance of institutional standards, this group of scholars examines how dimensions such as gender, ethnicity, and social class function to generate distinctions that also serve as a basis for social exclusion. Employing mostly micro-interpersonal methods (ethnography and interviews), their findings not only highlight the arbitrary nature of institutional imposition within different social contexts, but also underscore the importance of considering how the individual strategic use of knowledge, abilities, and skills produce benefits within different fields (Lareau \& Weininger, 2004).

Bourdieu and Passeron (1990) explain that norms are developed and reproduced in society through the education system, which benefits the dominant class and oppresses others. For example, with regards to cultural capital, a dominant language is valued and language skills such as reading and writing in that dominant language are given priority over other skills. Therefore, those who speak the dominant language are at a greater advantage in school and in society. The relationship between cultural capital and educational capital is interdependent and conversion can occur in a variety of ways. The education system values cultural capital; however, as Bourdieu (1986) notes, it does not teach cultural capital

Cultural capital refers to the whole of culturally-induced gains that individuals have acquired through inheritance or from different channels during their life. The individual with cultural capital can achieve the most appropriate social life for $\mathrm{him} / \mathrm{her}$ better by foreseeing the surrounding changes waiting for him/her. Therefore, the volume of cultural capital acquired takes the individual to a different social position and functions in a way to distinguish him/her from the others. It has been determined that individuals with high cultural capital for which the variables such as educational background and lifestyle form the basis further realize the changes around them and demand for a more excellent social life (Arun, 2009). Many experimental studies (Cheadle, 2008; DiMaggio, 1982; Kingston, 2001; Symeou, 2007; Xu \& Hampden-Thompson, 2012) have determined that there is a positive relationship between cultural capital and educational achievement. 
Bourdieu made significant contributions to the emergence of the concept of cultural capital and to the foundation of cultural capital. According to Bourdieu, "there are no social classes, classes are in virtual states, on lines that are not clear, not given but as a matter to be done, spaces of differences in which they exist" (Bourdieu, 1995). The cultural capital on which Bourdieu discourses is considered to be all cultural accumulations that provide a socio-economic advantage. Cultural capital is the social and cultural knowledge of the society and the individual related to heritage, which makes social mobilization of individuals valuable (Yosso, 2005). Cultural capital indicates not only the acquisitions acquired from the family and the environment, but also latent powers, talents, and achievements that are acquired through education by one's own efforts or inherited in the body. Bourdieu emphasizes the differentiation of society in semi-autonomous social systems. "For example, the field of art, the field of religion, or the field of economy are subject to different logics: The economic field has emerged historically as a universe, in which "business is business," and in which principally the relationships of emotional kinship, friendship and love are excluded. On the contrary, the field of art was established by the rejection of the law of material gain or by its reversal "(Bourdieu \& Wacquant, 2003). Here, Bourdieu, while telling us that the difference between the field and system is struggles and historicity, expresses the idea that the field is the place of struggles and force relations which are in the transformation and change purpose. In other words, "fields are the localities of power relations; transcendental tendencies include objective possibilities. A field never orients to a direction by chance. In the same way, everything is not always possible or impossible" (Bourdieu, 2015).

\section{Purpose of the Study}

The main purpose of this study is to examine the relationship between teachers' self-efficacy and cultural capital levels. In this context, answers to the following questions were sought in the study:

In the quantitative part of the study:

1. What is the level of cultural capital competencies of teachers?

2. What is the level of self-efficacy perceptions of teachers?

3. How is the relationship between teachers' cultural capital competencies and self-efficacy?

4. Is the cultural capital competency of teachers a significant predictor of the self-efficacy perception?

In the qualitative part of the study:

In our two-stage study, depending on the results of the quantitative section: 
5. $34 \%$ of teachers' self-efficacy perceptions are explained by their cultural capital competencies. In other words, cultural accumulation has a share of one third in the formation of teachers' professional self-efficacy. According to the opinions of teachers, how is the one-third contribution of teachers' self-efficacy to cultural capital competencies formed and where does it originate from?

6. According to the results of the study, teachers' cultural capital competencies were determined to be at the "moderate" level. Teachers' cultural capitals are seized as intellectual accumulation, participation in cultural activities, cultural consciousness, the cultural potential they own around and in themselves. According to teacher opinions, what can be done to raise the level of cultural capital competency of teachers in each dimension?

\begin{abstract}
Method
This study has a mixed design in the explanatory mixed model. In the studies, qualitative and quantitative designs have strong and weak aspects (Glesne, 1992/2013). With the use of qualitative and quantitative designs together, it is thought that the research gains depth. In this regard, both quantitative and qualitative methods were used in the study. Explanatory mixed methods are mixed methods in which the researcher begins with quantitative research and tries to search specific results in the second stage (Y1ldırım \& Şimşek, 2006; Patton, 2002; Creswell, 2002, p. 17; Creswell \& Plano Clark, 2014). In this study, firstly, the cultural capital and self-efficacy levels of teachers were revealed and how much cultural capital explains self-efficacy was examined in the quantitative part, and in the second part, depth was brought to the study by posing questions to the participants with the structured interview form in the light of quantitative results.
\end{abstract}

\title{
Population and Sampling
}

\section{The Population and Sampling belonging to the Quantitative part of the Study}

The population of the study consists of 885,458 teachers working in Turkey (Ministry of National Education Strategy, 2016). Because of the difficulty in reaching the whole of the population, sampling was performed. The stratified sampling method was used to determine the participants. In the creation of the strata, the Ministry of Development was taken as the reference. The Ministry of Development gathered the provinces under six categories according to their development level, by assessing their socio-economic and cultural structures within the "SEGE (2011) Socio-Economic Development Ranking Survey of Provinces and Regions" (Republic of Turkey Ministry of Development, 2013). In this study, a province which is easy to reach based on the easy sampling method 
was selected from each category. The personal information of the participants is given in Table 1.

Table 1. Personal Information of the Participants in the Quantitative Part of the Study

\begin{tabular}{|l|l|c|c|c|c|c|}
\hline Variables & $\boldsymbol{f}$ & $\mathbf{\%}$ & Provinces & $\boldsymbol{f}$ & $\mathbf{\%}$ \\
\hline \multirow{5}{*}{ Gender } & Female & 1146 & 46.7 & $\begin{array}{c}\text { Istanbul (First degree } \\
\text { developed province) }\end{array}$ & 532 & 21.7 \\
\cline { 2 - 7 } & Male & 1306 & 53.3 & $\begin{array}{c}\text { Kayseri (Second degree } \\
\text { developed province) }\end{array}$ & 296 & 12.1 \\
\cline { 2 - 8 } & Total & 2452 & 100.0 & $\begin{array}{c}\text { Gaziantep (Third degree } \\
\text { developed province) }\end{array}$ & 480 & 19.6 \\
\hline \multirow{5}{*}{$\begin{array}{l}\text { Educational } \\
\text { Status }\end{array}$} & $\begin{array}{l}\text { Associate } \\
\text { Degree }\end{array}$ & 94 & 3.8 & $\begin{array}{l}\text { Elazı̆ (Fourth degree } \\
\text { developed province) }\end{array}$ & 321 & 13.1 \\
\cline { 2 - 8 } & $\begin{array}{l}\text { Bachelor's } \\
\text { Degree }\end{array}$ & 2068 & 84.3 & $\begin{array}{c}\text { Osmaniye (Fifth degree } \\
\text { developed province) }\end{array}$ & 265 & 10.8 \\
\cline { 2 - 8 } & $\begin{array}{l}\text { Master's } \\
\text { Degree }\end{array}$ & 290 & 11.8 & $\begin{array}{c}\text { Diyarbakir (Sixth degree } \\
\text { developed province) }\end{array}$ & 558 & 22.8 \\
\cline { 2 - 8 } & Total & 2452 & 100.0 & Total & 2452 & 100.0 \\
\hline
\end{tabular}

\section{The Study Group belonging to the Qualitative Part of the Study}

The study group of the qualitative part of the study consists of 29 teachers. The study group was selected from volunteer teachers by the use of the easily accessible sampling method. With regard to the adequacy of the number of the participants in the study, the researchers' belief that data saturation was reached was taken as the basis. According to Merriam (2013, p. 79), how many individuals the study group should include in qualitative studies is related to whether the researchers find the number of the obtained data sufficient. The personal characteristics of the participants in the qualitative part of the study are presented in Table 2:

Table 2. Personal Characteristics of the Participants in the Qualitative Part of the Study

\begin{tabular}{|l|c|c|c|}
\hline Teachers (T) & Gender & Income Level & Seniority \\
\hline T1 & Female & $2000-5000 \mathrm{TL}$ & $1-5$ years \\
\hline T2 & Male & $2000-5000 \mathrm{TL}$ & $1-5$ years \\
\hline T3 & Male & $2000-5000 \mathrm{TL}$ & $1-5$ years \\
\hline T4 & Male & $5001+\mathrm{TL}$ & $1-5$ years \\
\hline T5 & Male & $2000-5000 \mathrm{TL}$ & $1-5$ years \\
\hline T6 & Male & $2000-5000 \mathrm{TL}$ & $1-5$ years \\
\hline T7 & Female & $5001+\mathrm{TL}$ & $1-5$ years \\
\hline T8 & Female & $2000-5000 \mathrm{TL}$ & $1-5$ years \\
\hline T9 & Female & $5001+\mathrm{TL}$ & $1-5$ years \\
\hline T10 & Female & $2000-5000 \mathrm{TL}$ & $1-5$ years \\
\hline T11 & Female & $2000-5000 \mathrm{TL}$ & $1-5$ years \\
\hline T12 & Female & $2000-5000 \mathrm{TL}$ & $1-5$ years \\
\hline T13 & Female & $2000-5000 \mathrm{TL}$ & $1-5$ years \\
\hline
\end{tabular}




\begin{tabular}{|c|c|c|c|}
\hline T14 & Female & $5001+\mathrm{TL}$ & $1-5$ years \\
\hline T15 & Female & $2000-5000 \mathrm{TL}$ & $1-5$ years \\
\hline T16 & Female & $2000-5000 \mathrm{TL}$ & $1-5$ years \\
\hline T17 & Female & $2000-5000 \mathrm{TL}$ & $1-5$ years \\
\hline T18 & Female & $2000-5000 \mathrm{TL}$ & $1-5$ years \\
\hline T19 & Female & $5001+\mathrm{TL}$ & $1-5$ years \\
\hline T20 & Female & $2000-5000 \mathrm{TL}$ & $1-5$ years \\
\hline T21 & Female & $2000-5000 \mathrm{TL}$ & $1-5$ years \\
\hline T22 & Female & $2000-5000 \mathrm{TL}$ & $1-5$ years \\
\hline T23 & Male & $2000-5000 \mathrm{TL}$ & $1-5$ years \\
\hline T24 & Male & $2000-5000 \mathrm{TL}$ & $1-5$ years \\
\hline T25 & Female & $2000-5000 \mathrm{TL}$ & $1-5$ years \\
\hline T26 & Female & $2000-5000 \mathrm{TL}$ & $1-5$ years \\
\hline T27 & Female & $2000-5000 \mathrm{TL}$ & $1-5$ years \\
\hline T28 & Female & $2000-5000 \mathrm{TL}$ & $1-5$ years \\
\hline T29 & Female & $2000-5000 \mathrm{TL}$ & $1-5$ years \\
\hline
\end{tabular}

\section{Data Collection Tools}

Since there are two variables to be measured in the quantitative part of the study, two different scales were used. The "Cultural Capital Competency Scale" developed by Tösten (2014) was used to measure the cultural capital competency levels of teachers. The Cultural Capital Scale is a 5-point Likert-type scale in which the teachers' levels of participation in the items are answered by scoring from 1 to 5 numerically from less to more. The 4-dimensional scale consists of 30 items, and the variance explained by the explanatory factor analysis is $57 \%$.

When the model was tested by the confirmatory factor analysis, the model was found to be compatible $(\chi 2=1018.93, \mathrm{~N}=256, \mathrm{sd}=393, \mathrm{p}=0.00, \mathrm{RMSEA}$; 0.079; SRMR; 0.065; GFI; 0.79; CFI; 0.96; IFI; 0.97; NFI; 0.94). The dimensions of the scale were examined as intellectual accumulation, participation, cultural consciousness and cultural potential. The Cronbach's alpha internal consistency coefficient of the scale was found to be .94 , which was considered highly reliable. Cultural capital competencies for each dimension were found to be .089 in intellectual accumulation, .88 in participation, .82 in cultural consciousness and .87 in cultural potential. Some items related to each dimension in the dimensions of the scale can be exemplified as follows: "I have knowledge in the fields of science that carry cultural value", "I attend activities and courses for cultural purposes", "I am aware of the cultural potential of the city, in which I live", "I speak openly and comprehensible".

To measure teachers' self-efficacy levels in the study, the "Teachers' Selfefficacy Scale" developed by Tschannen-Moran and Woolfolk Hoy (2001) and adapted into Turkish by Çapa, Çakıroğlu, and Sarıkaya (2005) was used. The selfefficacy scale is a 5-point Likert-type scale in which the self-efficacy levels of teachers can be marked and scored from 1 to 5 as (1) indicating inadequate, (2) less than adequate, (3) somewhat sufficient, (4) quite sufficient, and (5) highly 
sufficient. The confirmatory factor analysis of the self-efficacy scale revealed that RMSEA was .061, compliance was $90 \%$, and item correlations ranged from .82 to .89. The self-efficacy scale is a total of 24 items with a single factor. The sample items for the scale are as follows: "How much can you succeed in reaching students, who are difficult to work with?" "How much can you ensure students' critical thinking?"

When the internal consistency coefficients are examined for the reliability of the scales, it is observed that in this study the internal consistency coefficient of the cultural capital consistency scale (Cronbach's Alpha value) is .94 and of the selfefficacy scale is .97 . It was concluded that both scales were reliable for their reliability values. Since a similar scale was used in the sample group for the validity of the study, the reconstruct validity was not tested, and expert opinions were found sufficient.

In the qualitative part of the study, the structured interview form prepared by the researchers was used. In the preparation of the interview form, the findings obtained from the quantitative part of the study were utilized. For the content validity of the measurement tool, attention was paid to preparing the questions covering the cultural capital dimensions in the literature. In the interview form, primarily questions about descriptive information of the participants were asked. Descriptive information includes gender, seniority, and income level of the family. The family income levels are categorized into two as 2,000-5,000 TL and $5001 \mathrm{TL}$ and above. The aim here is that the cultural capital is also related to socioeconomic indicators. In the interview form, the findings obtained from the quantitative part of the study were shared with the participants, and it was asked what the reasons for these might be. Moreover, questions about how cultural capital could be increased were included.

\section{Data Collection and Analysis}

In the quantitative part of the study, the measurement tool was applied by directly reaching the participants. Before the measurement tool was applied, the participants were briefly informed about the study, and it was emphasized that the application was performed on a voluntary basis. The participants were informed about the importance of the answers they would give to the items in the scale, enough time was given to fill in the scale forms. The forms were usually answered in the teachers' room and classrooms. All of the data obtained from 2,452 participants were processed. In the analysis of the data obtained from the study, descriptive statistics (frequency, arithmetic mean, standard deviation) in the personal information and level determination, Pearson correlation test in exhibiting the inter-variable relationship, and regression analysis in revealing how much the cultural capital competency explains self-efficacy were used. In the analyses, the $p$ $\leq 0.05$ level was taken as a basis. It was observed that the assumptions required for regression analysis were met, that the distribution was normal according to the skewness and kurtosis values and that the variances were homogeneous. 
In the qualitative part of the study, the interview form created was collected through face-to-face interviews conducted with the participants. Appropriate environments were selected to ensure that the interviews were healthy. Detailed information about the research was given to the participants before the interview, and the theoretical foundations and the results of the study were shared. The researchers tried to reflect the interviews that they had held with 29 people to the research neutrally as much as possible. Reliability in qualitative studies is assessed in the context of the convincing additional information the study adds to the literature (Yıldırım \& Şimşek, 2006, p. 265). In this sense, the information of the study group and most of the answers given by the participants were shared. The credibility of the research was increased in this way. In the analysis of the data, the content analysis technique was used. The content analysis process is based on making sense from the data. Before beginning the data analysis, for preparation the researcher should read up the data until he/she understands them (Creswell, 2002, p. 217). Therefore, the data in the interview form were examined one by one, evaluated together with the related notes, and the codes and frequencies were extracted and reported. Frequency analysis reveals the frequency of the units that are reached as a result of the analysis numerically. The extraction of the codes is primarily the division of a particular finding into units and then gathering these units into categories according to certain criteria (Yıldırım \& Şimşek, 2006; Bilgin, 2006, p. 18-19).

\section{Findings and Interpretation}

In this section, the data obtained in accordance with the sub-objectives of the study were expressed in tables, and the results of the tables were interpreted. For the first two sub-problems of the study, the arithmetic means and correlation states related to the teachers' cultural capital competencies and self-efficacy levels are presented in Table 3.

Table 3. Teachers' Cultural Capital Competency - Self-Efficacy Levels and the Correlation State Between Them

\begin{tabular}{|l|c|c|c|c|c|c|c|c|c|}
\hline Variables & $\boldsymbol{N}$ & $\boldsymbol{X}^{-}$ & $\boldsymbol{s s}$ & $\mathbf{1}$ & $\mathbf{2}$ & $\mathbf{3}$ & $\mathbf{4}$ & $\mathbf{5}$ & $\mathbf{6}$ \\
\hline Intellectual accumulation & 2452 & 3.54 & .76 & 1.00 & & & & & \\
\hline Participation & 2452 & 3.05 & .94 & .62 & 1.00 & & & & \\
\hline Cultural consciousness & 2452 & 3.55 & .91 & .66 & .66 & 1.00 & & & \\
\hline Cultural potential & 2452 & 3.87 & .79 & .60 & .52 & .60 & 1.00 & & \\
\hline Cultural capital total & 2452 & 3.48 & .71 & .91 & .83 & .83 & .75 & 1.00 & $\mathbf{. 5 5}$ \\
\hline Self-Efficacy total & 2452 & 3.79 & .70 & .51 & .37 & .48 & .50 & .55 & 1.00 \\
\hline
\end{tabular}

$* \mathrm{p}<.05$ 
When teachers' cultural capital competency levels are examined, it is observed that they are in general at the "moderate" level $\left(\mathrm{x}^{-}=3.48\right)$. However, the dimensions with the highest mean in the sub-dimensions of cultural capital are observed to be cultural potential $\left(\mathrm{x}^{-}=3.87\right)$, cultural consciousness $\left(\mathrm{x}^{-}=3.55\right)$, intellectual accumulation $\left(\mathrm{x}^{-}=3.54\right)$ and cultural participation $\left(\mathrm{x}^{-}=3.05\right)$. Teachers' self-efficacy is found to be "fairly adequate" $\left(\mathrm{x}^{-}=3.79\right)$.

When the correlation between teachers' cultural capital competencies and self-efficacy levels is examined, a moderately positive correlation is observed in Table $3(\mathrm{r}=.55 ; \mathrm{p}<.05)$. Accordingly, when the relationship between self-efficacy and the sub-dimensions of cultural capital competency is examined, it is observed that there are moderately positive relationships between self-efficacy and intellectual capital $(\mathrm{r}=.52 ; \mathrm{p}<.05)$, participation in social activities $(\mathrm{r}=.37 ; \mathrm{p}$ $<.05)$, cultural consciousness $(\mathrm{r}=.48 ; \mathrm{p}<.05)$, cultural potential $(\mathrm{r}=.50 ; \mathrm{p}$ $<.05)$, and moderately positive relationships betwenn self-efficacy and the total of cultural capital $(r=.55 ; p<.05)$.

Table 4. Regression Analysis Related to the Explanation of Teachers' SelfEfficacy by Their Cultural Capital Competency

\begin{tabular}{|l|c|c|c|c|c|}
\hline Predictor Variables & $\boldsymbol{R}$ & $\boldsymbol{R}^{2}$ & $\boldsymbol{B}$ & $\boldsymbol{T}$ & $\boldsymbol{p}$ \\
\hline Intellectual accumulation & \multirow{3}{*}{.583} & \multirow{3}{*}{.339} & .279 & 11.409 & $.000^{*}$ \\
\cline { 1 - 4 } & \multirow{3}{*}{ Participation } & & -.058 & -2.471 & $.014^{*}$ \\
\hline Cultural consciousness & & .179 & 7.084 & $.000^{*}$ \\
\hline Cultural potential & & .257 & 11.629 & $.000^{*}$ \\
\hline
\end{tabular}
$* \mathrm{p}<.05$

In Table 4, it is observed that teachers' cultural capital competencies explain their self-efficacy by $34 \%$. According to this, it is observed that the model, in which the effect of teachers' cultural capital competencies on self-efficacy is revealed, is significant $(\mathrm{p}<0.05)$. When the sub-dimensions of cultural capital competencies and " $\beta$ " values, in the prediction of self-sufficiency, are taken into account, it is observed that the most effective subdimensions are intellectual accumulation, cultural potential, cultural consciousness, and participation, respectively.

The question "34\% of teachers' self-efficacy perceptions are explained by their cultural capital competencies. In other words, cultural accumulation has a share of one third in the formation of teachers' professional self-efficacy. In your opinion, how is the one-third contribution of teachers' cultural capital competencies to self-efficacy formed and where does it originate from?" was asked to the teachers, and it was attempted to determine how a relationship between cultural capital and self-efficacy arises according to teachers' opinions. Although two teachers declared ideas in more than one category, three teachers did not express an idea. Teachers' statements are given in categories in Table 5. 
Table 5. Cultural Capital Self-Efficacy Relationship and Resource

\begin{tabular}{|l|c|}
\hline Codes & $\boldsymbol{F}$ \\
\hline The effects of cultural consciousness on self-efficacy & 2 \\
\hline The effects of intellectual accumulation on self-efficacy & 7 \\
\hline The effects of general cultural capital on self-efficacy & 15 \\
\hline The effects of cultural potential on self-efficacy & 3 \\
\hline Total & $\mathbf{2 9}$ \\
\hline
\end{tabular}

The most emphasized aspect of teachers' cultural capital and self-efficacy relationship and its resource is that cultural capital in general affects self-efficacy positively and cultural capital is a significant source of self-efficacy. The teachers firstly mentioned the effects of cultural consciousness on self-efficacy and indicated that it could be the source. The examples of teachers' statements given categorically are as follows:

Individuals shape their self-consciousness and capital with the cultural structure of the society in which they live and shape themselves by taking advantage of many factors such as feelings and behaviors. In the future, this cultural accumulation can affect how they look at events and even at students, and how they behave (T1).

It could be in the field of history. To know the history of our country from past to present and to know its geographical characteristics make many contributions to teachers in the cultural sense. The constitution and citizenship rights must be known. Besides, current events and news should be followed (T4). It may originate from having comprehensive knowledge in the areas such as history, culture, and guidance, and of course, the reflection of these on the occupation is natural (T5).

The teacher is not the person who only directly transfers the information he/she has learned. At the same time, he/she also shares his/her social and cultural experiences with us. Self-efficacy increases as a person is enriched from the cultural aspect. These concepts are directly related to each other (T8). I think that the effect of the general cultural knowledge of a teacher, his/her approach to different cultures on self-efficacy will be great (T11). Since people are influenced by the social environment they grow up in, they are also affected by cultures. Culture can contribute to the individual from the social point of view. In my opinion, it has a contribution to teachers, especially from the social point of view (T14). Teachers, who are culturally rich, can gain confidence in themselves. At the same time, their communication with people/students in the classroom or around them gets easier. The self-expression power improves (T16).

Teachers are individuals who carry the values of the society they belong to and who transmit them most accurately through education and training. This situation will affect their communication with students and the approach of students to them (T17). Communication skills should be high. Being aware of their own culture and other cultural values and transferring this to his/her courses/students (T25). It would contribute to being able to adequately respond to the questions of students, expressing themselves better, and being able to show themselves as having knowledge and culture in a wide range of fields when required (T28). 


\section{Development of the Intellectual Accumulation Dimension}

The answers given to the question "How can we increase cultural capital in the Intellectual Accumulation dimension" directed to the teachers are presented in Table 6.

Table 6. Increasing the Intellectual Accumulation Dimension

\begin{tabular}{|l|c|}
\hline Codes & $\boldsymbol{F}$ \\
\hline Cultural activity & 12 \\
\hline Policy & 4 \\
\hline Research & 4 \\
\hline Reading & 9 \\
\hline Providing different opportunities & 2 \\
\hline Guidance & 2 \\
\hline Total & $\mathbf{2 9}$ \\
\hline
\end{tabular}

In order to increase teachers' intellectual accumulation dimension competencies, the most emphasized view is organizing cultural activities and participating in them, and reading books. Teacher expressions are presented in categories. Two teachers did not declare any ideas on this topic, but six teachers expressed opinions in more than one category. The examples of the teachers' opinions by the direct citations according to the categorical order in the table are as follows:

More excursions, more exhibitions have to be organized. Domestic and international visits should be arranged, and teachers should participate in informative seminars more (T8). To inform them, programs can be made. Cultural trips can be arranged, and training given under different conditions in different places can be provided to them. To reach the international level, international activities should be organized (T9). Any kind of activities like seminars and trips that require the active participation of teachers and students can be carried out (T12).

I think that intellectual accumulation must be acquired at a young age. For individuals, who cannot acquire it, education faculties at universities should be able to increase intellectual accumulation. For example, Erasmus is a very nice advantage. I think that in the courses, the programs that are based on research should be prepared (T14). Since intellectual accumulation is gained through education, I see the benefit of changing the process of becoming a teacher. It is not possible to provide this accumulation only with a group of teachers who are struggling to pass the exam. In the long term, a radical change is needed (T23).

Intellectual accumulation is provided mainly by schools, so there are lots of work to be done by universities. Research should be done at schools, and the scientific results of these studies should be transferred to students. Scientific publications should be made (T3).

The National Education could make compulsory for teachers to read some books related to the literature, science and cultural values (T17). The book reading rate can be increased. Reading can be made compulsory for both students and teachers (T25). 
Different conveniences can be provided to teachers and students by providing free transportation or digital subscriptions to libraries and contents throughout the city. By expanding the opportunities, environments that enhance intellectual accumulation can be created (T24).

Directing to different areas can be increased before the educational life ends and during the educational life. It can be given as responsibility and duty (T28).

In relation to the sixth sub-problem of the study, teacher statements related to developing the sub-dimensions of cultural capital are given respectively.

\section{Development of the Cultural Participation Dimension}

The answers given to the question "How can we increase cultural capital in the dimension of Cultural Participation" directed to the teachers are presented in Table 7.

Table 7. Increasing the Cultural Participation Dimension

\begin{tabular}{|l|c|}
\hline Codes & $\boldsymbol{f}$ \\
\hline Cultural activity & 19 \\
\hline Raising awareness & 6 \\
\hline Supporting & 2 \\
\hline Policy development & 2 \\
\hline Total & 29 \\
\hline
\end{tabular}

In order to increase teachers' cultural participation dimension competencies, the most emphasized dimension is cultural activity. The examples of the teachers' opinions according to the categorical order stated in the table are as follows:

Within the scope of significant cultural differences in Turkey between East and West, teachers may come across major obstacles. Providing knowledge and experience about the cultural structure of different regions preclude many problems and disruptions in the life of the teacher (T1). Activities such as directing to the theater, exhibition and cinema areas according to the interests, making more frequent trips and creating interaction with the cultures of neighboring countries could be carried out (T6). We must ensure that teachers participate in various trips, conferences, and social activities (T11).

Seminars ensuring that teachers become conscious and in which participation is mandatory can be organized. Awareness courses for different areas of interest can also be arranged (T9). Like the advertisement of a product, acculturation should also be advertised, since a teacher with low awareness is unlikely to become aware and motivate himself/ herself in this respect. At least, I think it is necessary to draw interest and to raise awareness about developing themselves (T20).

It should be ensured that teachers can participate in such cultural activities. For example, time must be given to them by reducing their workloads (T22). 
Annual plans for cultural participation can be given to schools. For example, elementary school $x$ must attend the $A, B, C$ museums, $X$ city and $Y$ exhibition during the 2019-2020 academic year. In the beginning, it will seem like an external motivation, but if it is understood that it is loved, it will turn into internal motivation (T23).

\section{Development of the Cultural Consciousness Dimension}

The answers given to the question "How can we increase cultural capital in the dimension of Cultural Consciousness" directed to the teachers are presented in Table 8 .

Table 8. Increasing the Cultural Consciousness Dimension

\begin{tabular}{|l|c|}
\hline Codes & $\boldsymbol{f}$ \\
\hline Supporting & 3 \\
\hline Education and training & 13 \\
\hline Cultural activity & 16 \\
\hline Total & $\mathbf{2 9}$ \\
\hline
\end{tabular}

In order to increase the teachers' cultural consciousness dimension competencies, the most emphasized opinion is determined as to provide participation by organizing cultural activities and to train by providing education. Teacher expressions are presented in categories. Although a teacher did not declare any idea on this issue, four teachers expressed opinions in more than one category. The examples of the teachers' opinions in categorical order are as follows:

I do not think teachers participate in cultural activities in this regard. The visits to museums or historical places are at the minimum level because of either financial aspect or the aspects of different interests. Probably once in a month, separate budget for such events, or incentive materials may be given (T1).

Seminars about the importance of culture can be organized. I am sure that teachers will become more conscious in this regard. The importance of being cultured should also be grasped (T12). In-service seminars can be held for teachers on cultural issues (T22). Courses that are related to culture, or enhancing cultural consciousness can be added to teacher training programs (T13).

This consciousness can be increased by traveling a lot, an individual who travels a lot knows a lot, becomes aware of the culture (T10). Teachers should take their students to a museum, a theater or an outdoor trip to inform them about artistic activities at least once a month, by cooperating with the school principal and teachers (T15). Teachers can be exchanged with teachers in other cities once a month to visit the cities for three days. Of course, this program should be supported by the National Education (T17). Within the scope of the school, visits to places of cultural value can be organized starting from the immediate vicinity (T25). Teachers and students should be able to go abroad by benefiting from international exchange 
programs, in order to gain awareness of different cultures and to provide at least one foreign language learning (T26). More activities such as movies, cinema, theater, etc. that reflect our culture can be organized, and students' participation can be encouraged (T29).

\section{Development of the Cultural Potential Dimension}

The answers given to the question "How can we increase cultural capital in the dimension of Cultural Potential" directed to the teachers are presented in Table 9.

Table 9. Increasing the Cultural Potential Dimension

\begin{tabular}{|l|c|}
\hline Codes & $\boldsymbol{f}$ \\
\hline Education and training & 21 \\
\hline Reading & 3 \\
\hline Cultural activity & 2 \\
\hline Supervising & 1 \\
\hline Total & $\mathbf{2 9}$ \\
\hline
\end{tabular}

The most emphasized opinion for enhancing the teachers' cultural potential dimension competencies is to give education to the student or teacher and training. Teacher expressions are presented in categories. Four teachers did not declare any ideas on this issue, but two teachers reported ideas in more than one category. Teacher opinions are given below in categorical order.

Diction courses, clear and comprehensible talking can be encouraged. More attention can be given to reading books and talking (T1). Vocational and personal development courses can be organized. Courses can be given on subjects such as cooperation and communication (T9). It must be ensured that teachers express themselves well, are open and comprehensible and that they are trained as a cultured person (T11). In my opinion, cultural potential should be given with some elective or compulsory courses at the university, or it can also be improved after graduation with some cultural activities for it (T13). Cultural potential can be increased with inservice training (T22). This actually ends in the person himself. Many factors such as family, school, a circle of friends can affect this. What we can do is to ensure that they have a say with entrepreneurship seminars. If it is thought to be inadequate, there may be diction and speech courses, but inviting a person of a certain age to this course may cause misunderstanding. Therefore, these courses and seminars should be given at the latest in university education (T23).

They should read more books (T2).

I think teachers should be supervised periodically throughout their professional lives so they can be individuals who continually develop. Of course, there should be supervision in a cultural sense. Moreover, he/she can participate in various projects in the sense of cultural potential, question himself/herself(T15). 
When the relationship between teachers' self-efficacy perceptions and cultural capital competencies is examined, it is observed that there is a "positive" relationship at the "moderate" level. This is the answer for the Research Question 3 .

The cultural capital competencies that teachers had were found to be a significant predictor of self-efficacy perceptions. It was observed that the teachers put forward mainly intellectual accumulation when they were asked how cultural capital competencies and how the areas in which cultural capital competencies contribute to the perception of self-efficacy could be increased. The most mentioned areas by the teachers in relation to the things that could be done to increase cultural capital competencies were reading, participation in cultural activities, cultural education, and training. This is the answer for the Reseach Question 4.

\section{Discussion}

This study aims to determine the self-efficacy and cultural capital competency levels of teachers and to reveal the relationship between them. According to the research findings, it is observed that the cultural capital competency levels of teachers are "moderate." Likewise, Tösten (2017) found out that teachers' cultural capital competency levels were "moderate" in their studies conducted on Hotel Management and Tourism Vocational High School teachers. However, Tösten (2015) determined that teachers' cultural capital competency levels were "high."

As a result of the study, it is observed that the teachers' self-efficacy level is "quite adequate." The results of the studies carried out on self-efficacy perceptions show that there are evaluations at different levels and types in relation to teachers' self-efficacy perceptions. In the study conducted by Doğan (2013), primary school teachers were studied, and it was determined that the primary school teachers' self-efficacy was at the moderate level. In the study conducted by Kahyaoğlu and Yangin (2007), it was determined that pre-service teachers' self-efficacy was quite sufficient. In the study carried out by Akdere (2012), it was determined that the self-efficacy of pre-service teachers was at the average level. This finding is parallel to the findings of Kahyaoğlu and Yangın (2007), Akdere, and Doğan. However, the finding obtained from the study conducted by Aktağ and Walter (2005), which reveals that the self-efficacy of physical education pre-service teachers is "above the average," differs from the findings of this study.

Teachers with high self-efficacy teach in a more effective and academicfocused way in the class and provide more different and successful feedbacks that will enrich the teaching environment compared to teachers with low self-efficacy (Gibson \& Dembo, 1984; as cited Tschannen-Moran \& Hoy, 1998). Teachers with a high level of self-efficacy have the ability to recover quickly in difficult situations, in the face of setbacks, by showing patience and effort (TschannenMoran \& Hoy, 1998). Teachers with high self-efficacy perceptions prefer a collaborative working environment and exhibit a more explicit attitude towards organizations and changes related to teaching and staff development (Collins et al., 
2002). As teacher competency increases, more humanistic approaches to the control of students manifest themselves (Goddard \& Goddard, 2001), and commitment to teaching comes to the forefront (Coladarci, 1992). Teachers' selfefficacy perceptions are their perceptions related to the ability to influence their student's performance of success. Self-efficacy beliefs in the field of education are evaluated for the purpose of explaining individual differences in the performances of teachers and understanding and improving teachers' behaviors (Demirtaş, Cömert, \& Özer, 2011; Kurt, 2012). It is observed that teachers with the high selfefficacy perception level have higher motivation levels, make more effort to teach, and experience lower levels of stress (Oğuz, 2009; Demirtaş, Cömert, \& Özer; Kurt, 2012). On the contrary, when teachers' self-efficacy beliefs begin to decrease, a transformation toward exhaustion starts, physical and emotional tiredness may be accompanied by the loss of self and sense of uselessness (Kurt, 2012). Upon examining the studies conducted, it is possible to say that teachers with the high self-efficacy perception are very different from other teachers in the teaching process and that they give the basic subjects to students successfully. According to the results of the study, it is stated that teachers with the high selfefficacy belief exhibit features such as being zealous in the teaching process, being quick in making instructional decisions, willingness to teach, susceptibility to applying new ideas and methods, and criticizing less when students make mistakes (Özenoğlu Kiremit, 2006). If it is thought what the teacher and the educational process could gain through self-efficacy, making efforts to identify and increase the supporting components of self-efficacy, such as cultural capital, may be regarded as important. It appears that there is a moderately positive relationship given the correlation between teachers' cultural capital competencies and their self-efficacy levels. In the study of Tösten (2017), they found a moderately positive relationship between teachers' cultural capital competency levels and their self-efficacies. Teachers expressed an opinion that cultural capital positively affects self-efficacy. In other words, they expressed an idea that by nature there is a positive relationship between cultural capital and self-efficacy. Besides, the view that cultural capital competencies can be increased mostly with cultural activities and education has emerged. A moderately positive correlation was determined between cultural capital and self-efficacy. In the interviews, teachers stated that cultural capital and self-efficacy are intertwined by nature, and it is reasonable that cultural capital acquisition affects self-efficacy positively. In this regard, Tösten (2017) achieved similar results in their studies.

It was concluded that teachers' cultural capital competencies explain a part of their self-efficacy. In this case, it can be said that the model, in which the effect of teachers' cultural capital competencies on self-efficacy is revealed, is meaningful. When the sub-dimensions of cultural capital competencies and " $\beta$ " values, in the prediction of self-efficacy, are taken into consideration, it is observed that the most effective subdimensions are intellectual accumulation, cultural potential, cultural consciousness, and participation, respectively. Tavakoli, Pahlavannezhad, and Ghansooly (2017) found out that there was a positive relationship between teachers' cultural capital competencies and their self-efficacy. Teachers with a high level of cultural capital competency have directly proportionally high self-efficacy 
levels. Similarly, this result was supported by the study carried out by Tösten (2017), in which it was observed that teachers' cultural capital competencies explain 33\% of their self-efficacy. Gibbs (2002) classified teachers' self-efficacy into four categories and also included cultural self-efficacy in self-efficacy elements. Cultural self-efficacy is the belief in the ability of a teacher to perform certain actions in culturally appropriate ways in certain teaching situations. Furthermore, effective teachers know well that students can learn in the best way, when students' cultures, backgrounds, and abilities are accepted by the teacher, and when the methodology and procedures are adapted to students (Zeichner, 1993). As a matter of fact, in the interviews, teachers expressed that in general, cultural capital involves cultural competencies due to its structure and it contributes to self-efficacy directly and indirectly.

When all these results are considered, in order to increase self-efficacy which has an important place in ensuring the productivity of teachers, it is necessary also to increase the cultural capital competency, which is at the "moderate" level. As indicated in the interviews with teachers, the things to be done to increase cultural capital competencies in each sub-dimension can be listed as follows: In the intellectual accumulation dimension, organizing cultural activities, increasing the rate of research and reading, directing correctly, and providing guidance. In the participation dimension, cultural activities, raising awareness for self-improvement of the individual, supporting, and policy development. In the cultural consciousness dimension, educational opportunities, professional development, cultural activities, material and spiritual support. In the cultural potential dimension, educational opportunities, professional development, reading, cultural activities and the supervision of development.

\section{References}

Akdere, N. (2012). Turkish pre-service teachers' critical thinking levels, attitudes and selfefficacy beliefs in teaching for critical thinking. Unpublished $\mathrm{PhD}$ Thesis.

Aktağ, I., \& Walter, J. (2005). Öğretmen adaylarının mesleki yeterlik duygusu [Preservice teachers' sense of professional qualification]. Spormetre, 3(4), 127-131.

Alivernini, F., \& Lucidi, F. (2011). Relationship between social context, self-efficacy, motivation, academic achievement, and intention to drop out of high school: A longitudinal study. Journal of Educational Research, 104(4), 241-252.

Arun, Ö. (2009). Yaşlı bireyin Türkiye serüveni: Türkiye'de yaşlı bireyler arasında kültürel sermaye dağılımı [The adventure of an elderly individual in Turkey: distribution of cultural capital among the elderly in Turkey]. Gaziantep Üniversitesi Sosyal Bilimler Dergisi, 8(1).

Azar, A. (2010). Secondary school science and mathematics pre-service teachers' selfefficacy beliefs. ZKÜ Social Sciences Journal, 6(12), 235-252.

Balc1, E. (1991). Roles of teachers. Educational Sociology. Ankara.

Bandura, A. (1986). Social foundations of thought and action: A social cognitive theory. Englewood Cliffs, NJ: Prentice- Hall, Inc.

Bandura, A. (1989). Social cognitive theory. Annuals of Child Development, 6, 1-60. Greenwich, CT: Jai Press LTD. 
Bandura, A. (1994). Self -efficacy. In Encyhopedia of Human Behavior, V.S. Ramachaudran (ed.), vol. 4, (pp. 71-81). New York: Academic Press. (Reprinted in H. Friedman (ed.), Encylopedia of Mental Health. San Diego: Academic Pres, 1998. Retrieved from http://www.des.emory.edu/mfp/banEncy.html.

Bandura, A. (1997). Self-efficacy: Toward a unifying theory of behavior change. Psychological Review, 84, 191-215.

Bandura, A. (ed.) (1995). Self-efficacy in changing societies. New York: Cambridge University Press.

Bek, Y. (2007). Teacher's Social/ Professional Roles and Status.Trakya University, Social Sciences Institute. Unpublished Master's Thesis, Edirne.

B1kmaz, F. H. (2006). Self-efficacy beliefs in science teaching and views about the effective science course. Educational Researches, 25, 34- 44.

Bilgin, N. (2006). Content Analysis in Social Sciences. Ankara: Siyasal Publishing

Blackledge, A. (2001). The wrong sort of capital: Bangladeshi women and their children's schooling in Birmingham, U.K. International Journal of Bilingualism, 5(3), 345-369.

Bourdieu, P. (1986). The forms of capital. In Handbook of Theory and Research for the Sociology of Education, J. G. Richardson (ed.), (pp. 241-258). New York, NY: Greenwood.

Bourdieu, P., \& Passeron, J.-C. (1990). Reproduction in education, society and culture (2nd ed.). London, UK: Sage.

Bourdieu, P. (1995). Practical Reasons. Translated by Hülya Tufan. İstanbul: Kesit Publishing.

Bourdieu, P. (2015). Sociological usage of the science: For Clinical Sociology of Scientific Field. Translated by L. Ünsaldi. Ankara: Heretik Publishing.

Bourdieu, P., \& Wacquant, L. J.D. (2003). The Answers for Reflexive Antrpology. Translated by Nazlı Ökten. İstanbul: İletişim Publishing.

Bussey, K., \& Bandura, A. (1999). Social Cognitive Theory of Gender Development and Differentiation. Psychological Review, 106(4), 676-713.

Cheadle, J. (2008). Educational investment, family context, and children's math and reading growth from kindergarten through the third grade. Sociology of Education, $81(1)$, s. $1-31$.

Cheng, S.T. (2011). Cultural Capital, Economic Capital, and Academic Achievement: Some Evidence from Taiwan. Proceedings of the IASA-IOS Joint Workshop of Young Sociologists, University of Tokyo, Japan.

Coladarci, T. (1992). Teachers' sense of efficacy and commitment to teaching. Journal of Experimental Education, 60(4), 323-337. http://dx.doi.org/10.1080/00220973. 1992.9943869

Collins, K. M. T., James, T. L., Minor L. C., Onwuegbuzie, A. J., Witcher, L. A., \& Witcher, A. E. (2002). Relationship between teacher efficacy and beliefs about education among preservice teachers. Paper Presented at the Annual meeting of the Mid-South Educational Research Association, Chattanooga, TN, November 6, 2002. http://www.eric.ed.gov/ERICDocs/data/ericdocs2sql/content_storage_01/ 0000019b /80/1a/eb/a7.pdf.

Creswell, JW. (2002). Educational research: Planning, conducting, and evaluating quantitative and qualitative approaches to research. Upper Saddle River, NJ: Merrill/Pearson Education.

Creswell, J. W., \& Plano Clark, V. L. (2014). Conducting Design of mixed method studies. Translation editors Dede, Y., ve Demir S. B. Ankara: An1 Publishing.

Çapa, Y., Çakıroğlu, J., \& ve Sarıkaya, H. (2005). The validity and reliability study of the Turkish adaptation of the teachers' self-efficacy scale. Eğitim ve Bilim. 30(137), 7481 
De Graaf, N. D., De Graaf, P. M., \& Kraaykamp, G. (2000). Parental cultural capital and educational attainment in the Netherlands: A refinement of the cultural capital perspective. Sociology of Education, 73(2), 92-111.

DeMarrais, K.B., \& LeCompte, M. D. (1998). The way schools work: A sociological analysis of education. New York, NY: Addison-Wesley.

Demirtaş, H., Cömert, M., \& Özer, N. (2011). Pre-service teachers' self-efficacy beliefs and attitudes towards the profession. Education and Science, 36(159).

DiMaggio, P. (1982). Cultural capital and school success: the impact of status culture participation on the grades of U.S. high school students. American Sociological Review, 47, 189-201.

Doğan, S. (2013). Examination of primary school teachers' self-efficacy perceptions and their attitudes towards the teaching profession. Unpublished Master's Thesis. Erzincan University Social Sciences Institute, Erzincan.

Eccles, J. S., \& Wigfield, A. (2002). Motivational beliefs, values, and goals. Annual Review of Psychology, 53, 109-132.

Gibbs, C. (2002). Effective Teaching: exercising self-efficacy and thought control of action. Paper presented at the Annual Conference of the British Educational Research Association, University of Exeter, England.

Gibson, S. \& Dembo, M. H. (1984). Teacher efficacy: a construct validation. Journal of Educational Psychology, 76(4), 569-582.

Glesne, C. (1992/2013). Becoming Qualitative Researches. Translated by Ersoy, A. and Yalçınoğlu. Ankara: Anı Publishing.

Goddard, R. D., \& Goddard, Y. L. (2001). Multilevel analysis of the relationship between teacher and collective efficacy in urban schools. Teaching and Teacher Education, 17, 807-818.

Goddard, R. D., Hoy, W. K., \& Woolfolk-Hoy, A.W. (2000). Collective teacher efficacy: its meaning, measure, and impact on student achievement. American Educational Research Journal, 37(2), 479-507.

Kahyaoğlu, M., \& Yangın, S. (2007). Views of elementary school pre-service teachers about their professional self-efficacy. Kastamonu Education Journal, 15(1), 73-84.

Kalmijn, M., \& Kraaykamp, G. (1996). Race, cultural captial, and schooling: An analysis of trends in the United States. Sociology of Education, 69, 22-34.

Kaptan, F. and Korkmaz H. (2001). Effect of science teaching based on collaboration on self-efficacy levels of pre-service teachers, IV. Science Education Congress, Ankara.

Kim, B. S. K., \& Omizo, M. M. (2005). Asian and European American cultural values, collective self-esteem, acculturative stress, cognitive flexibility, and general selfefficacy among Asian American college students. Journal of Counseling Psychology, 52, 412-419.

Kingston, P. W. (2001). The unfulfilled promise of cultural capital theory. Sociology of Education, extra Issue, s. 88-99.

Kurt, T. (2012). Teacher's self-efficacy and collective competence perceptions. Journal of Turkish Educational Sciences, 10(2), 195-227.

Lareau, A. (2003). Unequal childhoods: class, race, and family life. Berkeley: University of California Press.

Lareau, A. (2015). Cultural knowledge and social inequality. American Sociological Review, 78(4), 633-661. http://doi.org/10.1177/0003122413491963.

Lareau, A., \& Weininger, E. B. (2004). Cultural capital in educational research. In After Bourdieu: Influence, Critique, Elaboration, D. L. Swartz \& V. L. Zolberg (eds.), (pp. 105-144). Dordrecht, The Netherlands: Kluwer Academic Publishers. 
MEB İstatistikleri (Mone Statistics) (2015-2016). Retrieved from http://sgb.meb.gov.tr/ meb_iys_dosyalar/2016_03/18024009_meb_istatistikleri_orgun_egitim_2015_2016. pdf.

Merriam, S. (2013). Qualitative Research. (Çev. Ed.) Turan, S. Nitel Araştırma Desen ve Uygulama için Bir Rehber [A Guide to Qualitative Research Design and Implementation]. Ankara: Nobel Yay.

Oğuz, A. (2009). Sinıf ögretmeni adaylarının akademik öz-yeterlik inançları [Academic self-efficacy beliefs of pre-service primary school teachers]. VIII. Ulusal Sinif Öğretmenliği Eğitimi Sempozyumu. 21-23 Mayıs 2009. Eskişehir.

Özenoğlu Kiremit, H. (2006). Comparison of pre-service science teachers' self-efficacy beliefs in teaching biology. Unpublished Dissertation. Izmir Dokuz Eylul University Educational Sciences Institute.

Patton, M.Q. (2002). Qualitative Research and Evaluation Methods. Thousand Oaks, CA: Sage.

Scholz, U., Gutiérrez-Doña, B., Sud, S., \& Schwarzer, R. (2002). Is general self-efficacy a universal construct? Psychometric findings from 25 countries. European Journal of Psychological Assessment, 18(3), 242-251.

Symeou, L. (2007). Cultural capital and family involvement in children's education: Tales from two primary schools in Cyprus. British Journal of Sciology of Education, 28(4), s. 473-487.

Şahin, E. (2010). The effect of instructional style preferences and genders on self-efficacy levels of elementary school classroom teachers, IV. Congress of Science Education, 2000, Ministry of National Education: Ankara.

Tavakoli, F. H., Pahlavannezhad, M.R., \& Ghonsooly, B. (2017). A mixed methods study of the relationship between cultural capital of senior high school english teachers and their self-efficacy in tran's english language classrooms. https://us. sagepub.com/en-us/nam/open-access-at-sage.

TCKB (2013). (SEGE-2011). Research of Socio-Economic Development Rankings of Provinces and Regions, The Republic of Turkey Ministry of Development publishing, Ankara.

Tösten, R. (2015). The investigation of teachers' cultural capital competencies. Unpublished Dissertation. University of Gaziantep, Social Sciences Institute, Gaziantep.

Tösten, R. (2014). Cultural capital scale: validity and reliability study. International Journal of Social Science Research.

Tösten, R. (2017). The relationship between cultural capital qualification levels and selfefficacy levels of hotel management and tourism vocational high school teachers. Academical View Journal, 64(November-December).

Tschanen-Moran, M., \& Woolfolk, A. H. (1998). Teacher efficacy: 1ts meaning and measure. Review of Educational Research, 68, 202-248.

Tschannen-Moran, M., \& Woolfolk-Hoy, A. (2001) Teacher efficacy: Capturing an elusive concept. Teaching and Teacher Education, 17, 783-805.

Werfhorst, H. G. V. D., Sullivan, A., \& Cheung, S.-Y. (2003). Social class, ability and choice of subject in secondary and tertiary education in Britain. British Educational Research Journal, 29(1), 41-62.

White, K. R. (1982). The relation between socioeconomic status and academic achievement. Psychological Bulletin, 91, 461448.

Woulfe, J. (2008). Self-efficacy and culture: A comparison of Denmark and the United States. Gustavus Adolphus College. Thesis. 
Xu, J., \& Hampden-Thompson, G. (2012). Cultural reproduction, cultural mobility, Cultural resources, or trivial effect? A Comparative approach to cultural capital and educational performance. Comparative Education Revie, 56(1), s. 98-124.

Yesilyurt, E. (2013). Teacher self-efficacy perceptions of pre-service teachers. Electronical Social Sciences Journal, 12, 88-104.

Yıldırım, A., \& ve Şimşek, H. (2006). Qualitative research methods in Social Sciences. Ankara: Seçkin Publishing.

Yosso, T. J. (2005). Whose culture has capital? A critical race theory discussion of community cultural wealth. Race Ethnicity and Education, 8(1), 69-91.

Zeichner, K. M. (1993). 16 Key elements of effective teacher education for diversity, educating teachers for cultural diversity (NCRTL special report), East Lansing, Michigan: National Center for Research on Teacher Learning, (ERIC Document Reproduction No. ED 359167). 